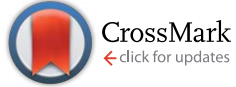

Cite this: J. Mater. Chem. A, 2016, 4, 16723

Received 25th June 2016

Accepted 25th September 2016

DOI: $10.1039 / \mathrm{c} 6 \mathrm{ta} 05347 \mathrm{e}$

www.rsc.org/MaterialsA

\section{Low powered, tunable and ultra-light aerographite sensor for climate relevant gas monitoring $\dagger$}

\author{
O. Lupan, ${ }^{\text {ab }}$ V. Postica, ${ }^{\text {b M. Mecklenburg, }}{ }^{c}$ K. Schulte, ${ }^{c}$ Y. K. Mishra, ${ }^{a}$ B. Fiedler ${ }^{c}$ \\ and R. Adelung ${ }^{a}$
}

Increasing atmospheric $\mathrm{CO}_{2}$ gas pollution and emergence of new types of green energy sources require continuous environmental monitoring. In this context, fast, efficient, light, robust, and reliable gas sensors that can work at room temperature are in high demand. We report on a low-powered type of ultra-light sensor, based on a 3-D-microtube network from a 2-D graphene/nanographite, called aerographite, and a method to tune the nanosensor's selectivity by a simple variation of the applied bias voltage. Adequate selectivity to $\mathrm{CO}_{2}$ and ultra-fast sensing of $\mathrm{H}_{2}$ by applying $1 \mathrm{~V}$ and $5 \mathrm{~V}$, respectively, is obtained. At ultra-low applied bias voltages (1-100 mV) only very low power consumption ( $\approx 3.6 \mathrm{nW}$ for $1 \mathrm{mV}$ ) is needed. This is most important, as it can be run by energy harvesting methods. The presented results are of the highest interest in terms of low-cost production of ultra-light and ultra-low-power consumption gas sensors for environmental monitoring of greenhouse gases and their simplicity from the technological/engineering points of view.

\section{Introduction}

Massive industrialization in the recent century and the phenomenal progress of new technologies enhance our daily life, as well as impact upon our lifestyle and social-economical organization today. Unfortunately, this process has not passed without consequences and one of the most important is air pollution with $\mathrm{CO}_{2}$ gas, which has progressively increased with a large impact on ocean acidification and greenhouse effects. ${ }^{2-5}$ Also important is the reduction of fossil fuel reserves as petroleum and coal, ${ }^{7}$ leading to an extensive search for new alternative sources of green energy. In this context, hydrogen fuel is very attractive because it is the most abundant element in the universe. ${ }^{\mathbf{1 0 , 1 1}}$ However, it has some limitations, being highly flammable and explosive by mixture with air, even at low concentrations (its lower flammability limit, LFL, is only $4 \%$ ). Therefore, the necessity arises to create gas sensors and nanosensors to monitor $\mathrm{CO}_{2}$ and $\mathrm{H}_{2}$ gas concentrations. For these purposes, continuous and highly porous three-dimensional (3-D) networks of semiconducting oxides ${ }^{12,13}$ and 2-D carbon based nanomaterials ${ }^{\mathbf{1 5}}$ have attracted great attention due to

${ }^{a}$ Functional Nanomaterials, Faculty of Engineering, Institute for Materials Science, Christian-Albrechts-Universität zu Kiel, Kaiserstr. 2, D-24143, Kiel, Germany. E-mail: ollu@tf.uni-kiel.de; lupanoleg@yahoo.com; ra@tf.uni-kiel.de

${ }^{b}$ Department of Microelectronics and Biomedical Engineering, Technical University of Moldova, 168 Stefan cel Mare Av., MD-2004 Chisinau, Republic of Moldova 'Institute of Polymers and Composites, Hamburg University of Technology, Denickestr. 15, D-21073 Hamburg, Germany.E-mail: schulte@tuhh.de; fiedler@tuhh.de

$\uparrow$ Electronic supplementary information (ESI) available. See DOI: $10.1039 /$ c6ta05347e their advanced properties obtained from the nanoscale. 2-D materials like graphene have typically the difficulty that they show their special properties only when they are isolated, such as when free standing. In this context, a recently synthesized rolled up 3-D framework material, called aerographite ${ }^{17}$ or graphene/nanographite, was demonstrated to posses a very low density $\left(<200 \mu \mathrm{g} \mathrm{cm}^{-3}\right)$ with high mechanical robustness $(e . g$. it withstands accelerations $>10 \mathrm{G}$ ). With its ultra-high porosity (meaning porosities $>99.99 \%$ ), ultra-light weight, flexibility, and the hollow nature of the interconnected graphene/nanographite based microstructures with nanoscopic wall thicknesses, it can be very easily handled and utilized. ${ }^{17}$ In contrast to conventional graphene-like 2-D materials, the graphite/graphene planes in aerographite are bent to moderate curvatures which stabilize, but have no electronic consequences like in carbon nanotubes (CNTs). This allows interconnections, in contrast to CNTs, thus aerographite forms seamless 3-D frameworks of macroscopic dimensions. Hollow structures and especially their networks, are known to provide more adsorption sites for gas molecules, leading to improved gas sensing properties. ${ }^{\mathbf{2 1 2 2}}$ Thus, aerographite or graphene/nanographite rolled up as a 3-D framework material appears to be an outstanding advanced material for novel devices for gas detection applications.

The possibility to synthesize large aerographite in large amounts allows also its processing in numerous small pieces and easy integration in sensor structures by simple mechanical fixation, such as clamping or with silver paste on pre-patterned substrates with gold electrodes, which do not need additional lithography steps for the fabrication of electrical contacts. Another important factor is its "low noise" nature and low 
electrical resistance at room temperature, ${ }^{15}$ which allows to integrate non-sophisticated electronic circuits for sensor structure control, which can be quite reliable, since no damage of the sensing material can occur. This makes aerographite more suitable or even ideal for integration in electronic circuits. In this context, room temperature gas sensing with carbon nanomaterials (carbon nanotubes and graphene) is very relevant from a practical point of view, because it excludes the necessity of heaters to reach the relevant operating temperature and considerably decreases the complexity and increases the simplicity of the fabrication process, involving fewer technological steps.

Here, we report for the first time on the room temperature gas sensing performance of devices and nanodevices based on the aerographite material family which can easily be tailored to different morphologies. The samples demonstrated variable selective properties dependent on the applied bias voltage. For aerographite from sample set A (microscopic tubes with a nanoscopic wall thicknesses $\approx 15 \mathrm{~nm}$ ) at low applied bias voltages ( $\mathrm{mV}$ range), the power consumption of the sensor devices was found to be ultra-low (in nW range). At $1 \mathrm{~V}$ applied bias voltage, a selective $\mathrm{CO}_{2}$ gas sensor can be obtained. With further increase of the bias voltage value (up to $5 \mathrm{~V}$ ) an ultra-fast and highly selective $\mathrm{H}_{2}$ detection was observed. Thus, an efficient modulation/tuning of selectivity of the aerographite (sample set A) based sensor can be achieved by a simple change in the value of the applied bias voltage at ultra-low power.

\section{Experimental}

The carbon based aerographite material (3D interconnected graphitic tetrapods) is synthesized via direction conversion of sacrificial porous zinc oxide ceramic templates in a chemical vapour deposition (CVD) process in a single step. The growth details and properties of aerographite have already been described in detail in previous works..$^{1723-25}$ The combination of custom template design and adjustment of the following CVD process for aerographite production enables tailorable properties of the material. The microstructure of aerographite is defined by the template morphology which is actually made from 3D networks of $\mathrm{ZnO}$ tetrapods. ${ }^{13}$ Aspect ratios, diameters and surface morphologies can be easily tuned in a broad manner. ${ }^{17}$ Basic aerographite configuration (hollow, with closed graphitic shells or graphene/nanographite rolled up as a 3-D framework material) can be obtained by placing $\mathrm{ZnO}$ templates in the maximum temperature zone of a two zone split tube furnace (quartz tube; length $=1300 \mathrm{~mm}$; diameter $=110 \mathrm{~mm}$ ) (see Fig. S1a $\dagger$ ). The temperature within the injection zone and the first half of the CVD reactor is constant at $200{ }^{\circ} \mathrm{C}$. The main zone of the furnace varies between $760-900{ }^{\circ} \mathrm{C}$. Ar gas flow acts as a protecting gas and for removal of in situ formed metallic zinc. Hydrogen and cracking products of toluene act as reducing atmosphere for the transition on $\mathrm{ZnO}$ to $\mathrm{Zn}$. All times and phases of variable carbon feeding and variable gas concentrations are given in Fig. S1b. $\dagger$

Sensor structures on interconnected 3-D graphene/nanographite tetrapods rolled up as a 3-D framework material were fabricated by the method reported previously for the fabrication of 3-D ZnO tetrapod networks, without subsequent annealing at high temperatures. ${ }^{13}$ Aerographite was cut into small pieces of $\sim 3 \times 3 \mathrm{~mm}$ and $\sim 1 \mathrm{~mm}$ thickness. These samples were connected to pre-patterned glass substrates with $\mathrm{Au} / \mathrm{Cr}(\sim 170 \mathrm{~nm} /$ $\sim 10 \mathrm{~nm}$ ) electrodes with silver paste. All gas sensing investigations were realized at room temperature as reported previously. ${ }^{26}$ Sensor devices were placed in a closed chamber connected to a gas flow system. The pre-calibrated mass flow controllers (MFC, Bronkhorst UK) were used for measurement and control of gas concentration. To obtain the necessary concentration, the target gas was mixed with ambient air (relative humidity of $\mathrm{RH}=30 \%$ ). In all experiments the total flow rate was maintained at $500 \mathrm{sccm}$. The electrical measurements were continuously monitored and collected using a computer-controlled Keithley 2400 source meter through LabView software (National Instruments) applying different bias voltages. All sensors demonstrated a typical p-type behavior, i.e. an increase in the resistance of the sensor upon exposure to reducing gases $\left(\mathrm{NH}_{3}, \mathrm{H}_{2}\right.$, and $\left.\mathrm{CH}_{4}\right)$ and a decrease in the resistance of the sensor upon exposure to oxidizing gases $\left(\mathrm{CO}_{2}\right) \cdot{ }^{15}$ The gas response was defined as:

$$
\left(\left(R_{\mathrm{gas}}-R_{\mathrm{air}}\right) / R_{\mathrm{air}}\right) \times 100 \%
$$

for all type of gases, where $R_{\text {air }}$ and $R_{\text {gas }}$ are the resistance of the sensor structure in air and under exposure to the tested gas, respectively. Response and recovery times were specified as the necessary time to reach $90 \%$ of the complete response and $10 \%$ of the recovery to the initial baseline, respectively. All measurements were performed for several sensor structures, demonstrating good reproducibility.

\section{Results and discussion}

\section{Morphology of aerographite material integrated in the developed sensor structure}

Fig. 1 and $\mathrm{S} 2 \uparrow$ present SEM images of the open porous structure of aerographite (sample set A) used for the sensor fabrications tested in this study at different magnifications. Since ZnO-tetrapod (ZnO-T) interconnected networks were used as a sacrificial template for the formation of aerographite from sample set A, the formed microscopic tubes with nanoscopic wall thicknesses ( $\approx 15 \mathrm{~nm}$, see Fig. S3†) follow the 3-D shape ${ }^{17}$ of the ZnO-T surface (Fig. 1c) and thus are interconnected similarly and seamlessly (Fig. 1d). A high concentration of tubular graphitic structures has open ends (see Fig. 1e, f and S2b-d $\dagger$ ), which can also promote gas adsorption/desorption on the inside of the structures. ${ }^{27}$ XRD, Raman, and TEM measurements of aerographite in detail were presented in our previous work, ${ }^{17}$ while this work will be mainly focused on the gas sensing abilities of aerographite material with different morphologies at the nanopower consumption level. Sample set A is a closed-shell aerographite with medium thickness of the graphite walls and medium density. ${ }^{17}$ The temperature and gas profile follow that described in ref. 28; here a relative carbon feeding rate of $4 \mathrm{ml}$ per h per g_ZnO was used. 


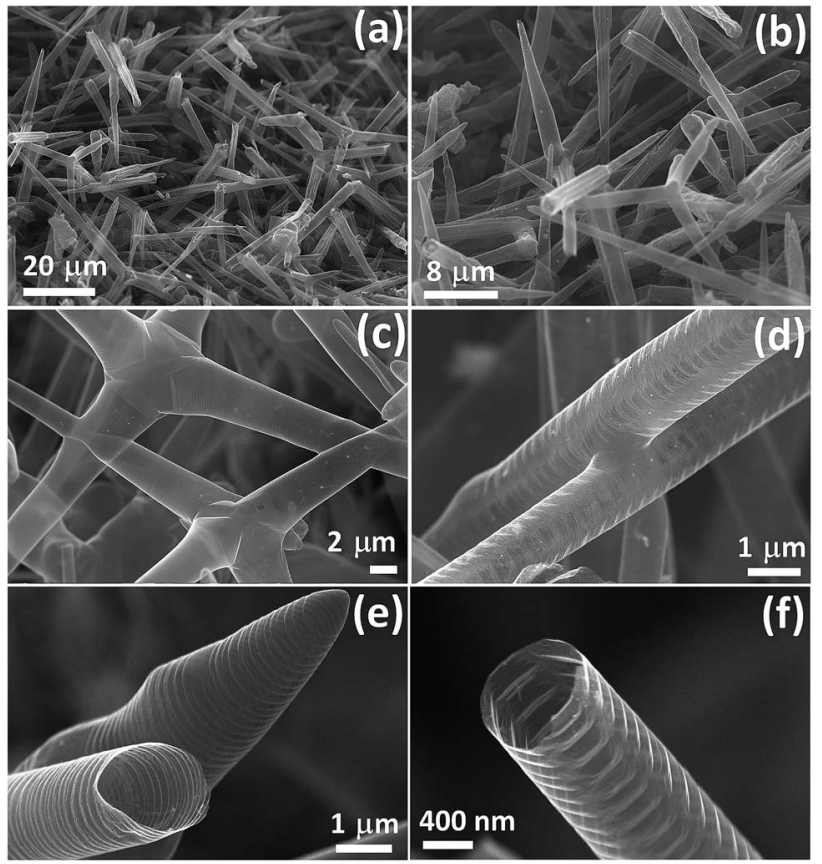

Fig. 1 SEM images of aerographite representing different magnifications of the graphene/nanographite material which is composed of 3D hollow graphitic tetrapods. (a) and (b) SEM images of the 3-D hollow interconnected graphitic tetrapods networks at lower and higher magnification, respectively. (c) SEM image for better visualization of the interpenetrated hollow nanographite tetrapods. (d) Interconnection between two graphitic tubes. (e) and (f) Demonstration of the closed and open end of the tubular and hollow graphitic structures with microscopic diameter and nanoscopic wall thicknesses.

\section{Device structure based on aerographite and electrical} measurements

Fig. 2a shows the sensor structure based on aerographite from sample set A used in this study for gas sensing and electrical measurements. The fabrication process is presented in the experimental part and in our previous work and it is similar for all types of aerographite material. ${ }^{13}$ Fig. S4a $\dagger$ presents the current-voltage characteristics of the sensor structure based on sample set A at room temperature and at $200{ }^{\circ} \mathrm{C}$. The structure shows a linear behavior for both negative and positive bias voltages in between the $-1 \mathrm{~V}$ to $+1 \mathrm{~V}$ region, and indicates the formation of ohmic contacts between the electrode and carbon microscopic tubes. However, at higher applied bias voltages an increase in current (decrease in resistance) can be observed. This effect can be related to the self-heating effect of the aerographite-based sensing material, as was already observed for other carbon based structures..$^{29-31}$ An increase in the current value at $200{ }^{\circ} \mathrm{C}$ may indicate a thermally activated electrical conduction of aerographite, i.e. an increase of thermionic emission current over a low potential barrier between graphite walls with increase in temperature. ${ }^{32}$ Other sensor structures based on sample sets B, C, and D showed the same linear behavior of current-voltage characteristics in this range (from $-1 \mathrm{~V}$ to $+1 \mathrm{~V}$ ) (see Fig. S4b†). Sample sets C and D demonstrated a much lower resistance, and cannot support bias voltages
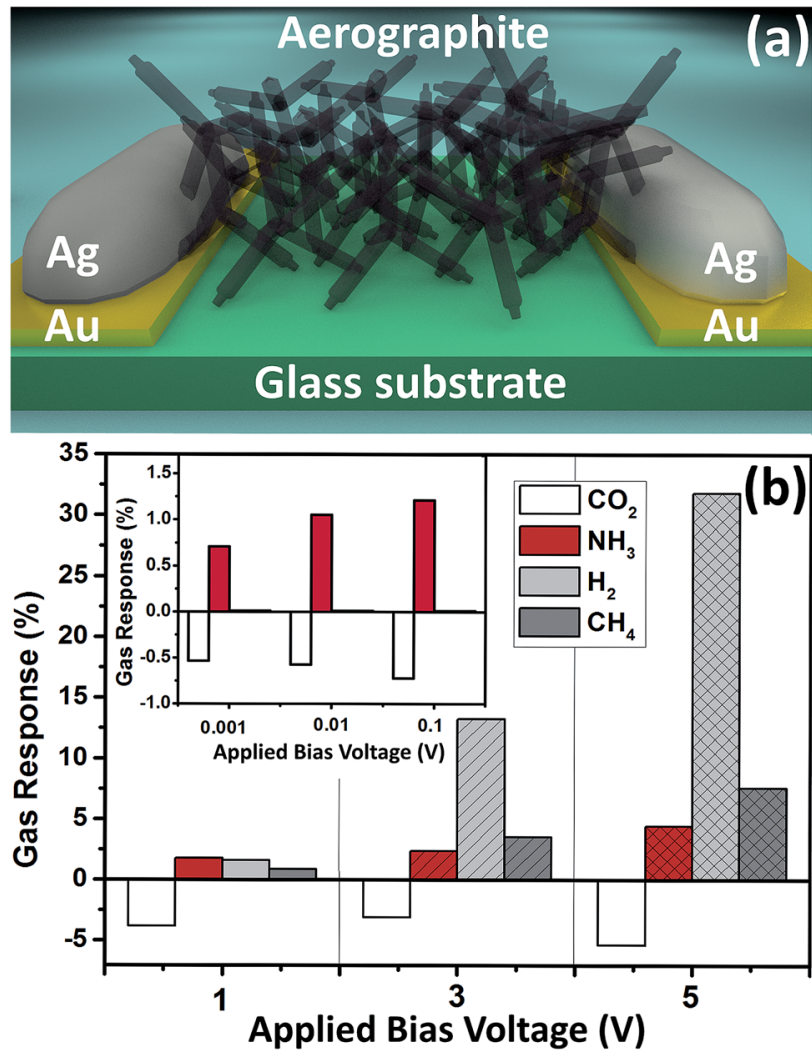

Fig. 2 (a) Structure of the gas sensor based on aerographite. (b) Gas response of aerographite versus the value of applied bias voltage at room temperature (concentrations of gases are the following: $\mathrm{CO}_{2}-$ 500 ppm, $\mathrm{NH}_{3}-100$ ppm, $\mathrm{H}_{2}-10000$ ppm, and $\mathrm{CH}_{4}-10000$ ppm).

higher than $2-3 \mathrm{~V}$, thus gas sensing measurements were performed only up to $1 \mathrm{~V}$. Fig. S5a $\uparrow$ shows the temperature dependence of the sensor device resistance based on sample set A measured in air. The resistance of sensor structures was measured in the range from $30^{\circ} \mathrm{C}$ to $384^{\circ} \mathrm{C}$ with an applied bias voltage of $0.1 \mathrm{~V}$ to exclude the self-heating effect. A linear decrease in resistance with increasing temperature was observed (see Fig. S5a†), similar to that reported for multiwalled carbon nanotubes (MWCNT) ${ }^{29}$ The measured temperature coefficient of resistance (TCR) of sample set $\mathrm{A}$ is about $-0.0353 \%$ per ${ }^{\circ} \mathrm{C}$, while for samples from sets B, C, and D the TCR are $-0.045 \%$ per ${ }^{\circ} \mathrm{C},-0.0486 \%$ per ${ }^{\circ} \mathrm{C}$, and $-0.0411 \%$ per ${ }^{\circ} \mathrm{C}$, respectively (see Fig. S5c and $\mathrm{d} \dagger$ ), and thus are in the range of bulk graphite. ${ }^{33}$

\section{Gas sensing investigations of aerographite based device structures}

Fig. $2 \mathrm{~b}$ presents the gas response of the sensor device structure based on sample set A versus the value of applied bias voltage at room temperature to $500 \mathrm{ppm}$ of $\mathrm{CO}_{2}, 100 \mathrm{ppm}$ of $\mathrm{NH}_{3}$, and $10000 \mathrm{ppm}$ of $\mathrm{H}_{2}$ and $\mathrm{CH}_{4}$, respectively. As can be observed from Fig. S4a, $\uparrow$ the resistance of the sensor structure was about $293 \mathrm{ohm}$ (at room temperature), thus at an applied bias voltage of $1 \mathrm{~V}$, a current of about $3.3 \mathrm{~mA}$ flow through the 3-D networks (Fig. S4a $\dagger$ ). At these operating parameters, the sensors showed 
a good gas response to $\mathrm{CO}_{2}$ gas, with $S_{\mathrm{CO}_{2}}=-3.83 \%$. By increasing the value of the applied bias voltage to $3 \mathrm{~V}$ and $5 \mathrm{~V}$, a considerable increase in $\mathrm{H}_{2}$ gas response $\left(S_{\mathrm{H}_{2}}\right)$ was observed (Fig. 2b). Thus, $S_{\mathrm{H}_{2}}$ increased from $1.58 \%$ at $1 \mathrm{~V}$ to $13.2 \%$ and $31.8 \%$ at $3 \mathrm{~V}$ and $5 \mathrm{~V}$ applied bias voltage, respectively. A slight increase in response for other gases was also observed (Fig. 2b). The selectivity factors for $\mathrm{H}_{2}$ gas at $3 \mathrm{~V}$ applied bias voltage are $S_{\mathrm{H}_{2}} / S_{\mathrm{NH}_{3}} \approx 5.5$ and $S_{\mathrm{H}_{2}} / S_{\mathrm{CH}_{4}} \approx 3.7$, while the following selectivity factors for $5 \mathrm{~V}$ applied bias voltage were calculated to be $S_{\mathrm{H}_{2}} / S_{\mathrm{NH}_{3}} \approx 7.15$ and $S_{\mathrm{H}_{2}} / S_{\mathrm{CH}_{4}} \approx 4.2$. These results demonstrated the excellent selectivity to $\mathrm{H}_{2}$ gas of aerographite based sensors (sample set A) at relatively high applied bias voltage by a higher increase of gas response to $\mathrm{H}_{2}$ gas.

To overcome the high power consumption of the sensor structures, devices based on aerographite from sample set A were also tested with gases at much lower applied bias voltages ( $<1 \mathrm{~V}$ ), namely $1 \mathrm{mV}, 10 \mathrm{mV}, 100 \mathrm{mV}$ (see inset from Fig. $2 \mathrm{~b}$ and 3). At such ultra-low applied bias voltages, a gas response was only observed with $\mathrm{CO}_{2}$ gas and $\mathrm{NH}_{3}$ vapour, while a gas response lower than $<0.1 \%$ was observed for $\mathrm{H}_{2}$ and $\mathrm{CH}_{4}$ gases. The respective current values with power consumption upon exposure to air for all applied bias voltages are represented in Table S1. $\dagger$ At a $1 \mathrm{mV}$ applied bias voltage, an extra low power consumption of $3.6 \mathrm{nW}$ was obtained. This value is lower or comparable with the power consumption for sensors based on a single metal oxide nanostructure ${ }^{34}$ or a single carbon based nanostructure. ${ }^{35}$ Gas and vapour detection even at an applied bias voltage of $1 \mathrm{mV}$ is possible due to the 'low noise' nature of the carbon based nanomaterials ${ }^{\mathbf{1 5}}$ (see Table $\mathrm{S} 1 \dagger$ ) and their low electrical resistance. Thus, aerographite from sample set A was found to be an excellent advanced material for extra-low power consumption sensing applications. Therefore, such sensor structures can be used for sensing applications that require long-term operation (from several to ten years) in inaccessible places, for example sending into space on balloons for permanent climate monitoring, where the power source cannot be changed, or low-power energy harvesting is employed. It can be also easily incorporated into smartphones by using the same cable as for headphones with four different power levels. Therefore, we investigated the long-term stability of the developed sensor structures to different gases and different conditions over one month. The results are presented in Fig. S6a. $\dagger$ Due to the room temperature operating conditions and low applied bias voltages $(1 \mathrm{mV}$ and $0.1 \mathrm{~V})$, which exclude the chemical and structural modifications, ${ }^{36}$ an excellent stability was obtained (see Fig. S6a $\dagger$ ). Meanwhile, a slight decrease in gas response was observed at a $1 \mathrm{~V}$ and $5 \mathrm{~V}$ applied bias voltage for the developed sensors (see Fig. S6a $\dagger$ ). In Fig. S6a $\dagger$ are also presented results for devices fabricated based on samples synthesized in 2012 which show totally unaffected performance, which confirms their long-term stability under ambient conditions.

The $\mathrm{H}_{2}$ gas response at $5 \mathrm{~V}$ applied bias voltage and $\mathrm{CO}_{2}$ gas response at $1 \mathrm{~V}$ applied bias voltage versus concentration of tested gases are presented in Fig. S6b and $c, \uparrow$ respectively, showing an almost linear dependence in the investigated range. ${ }^{14}$

The gas sensing properties of aerographite and other carbon based materials can be explained by the reducing and oxidizing characteristics of the tested gases and vapors $\left(\mathrm{CO}_{2}, \mathrm{NH}_{3}, \mathrm{H}_{2}\right.$,
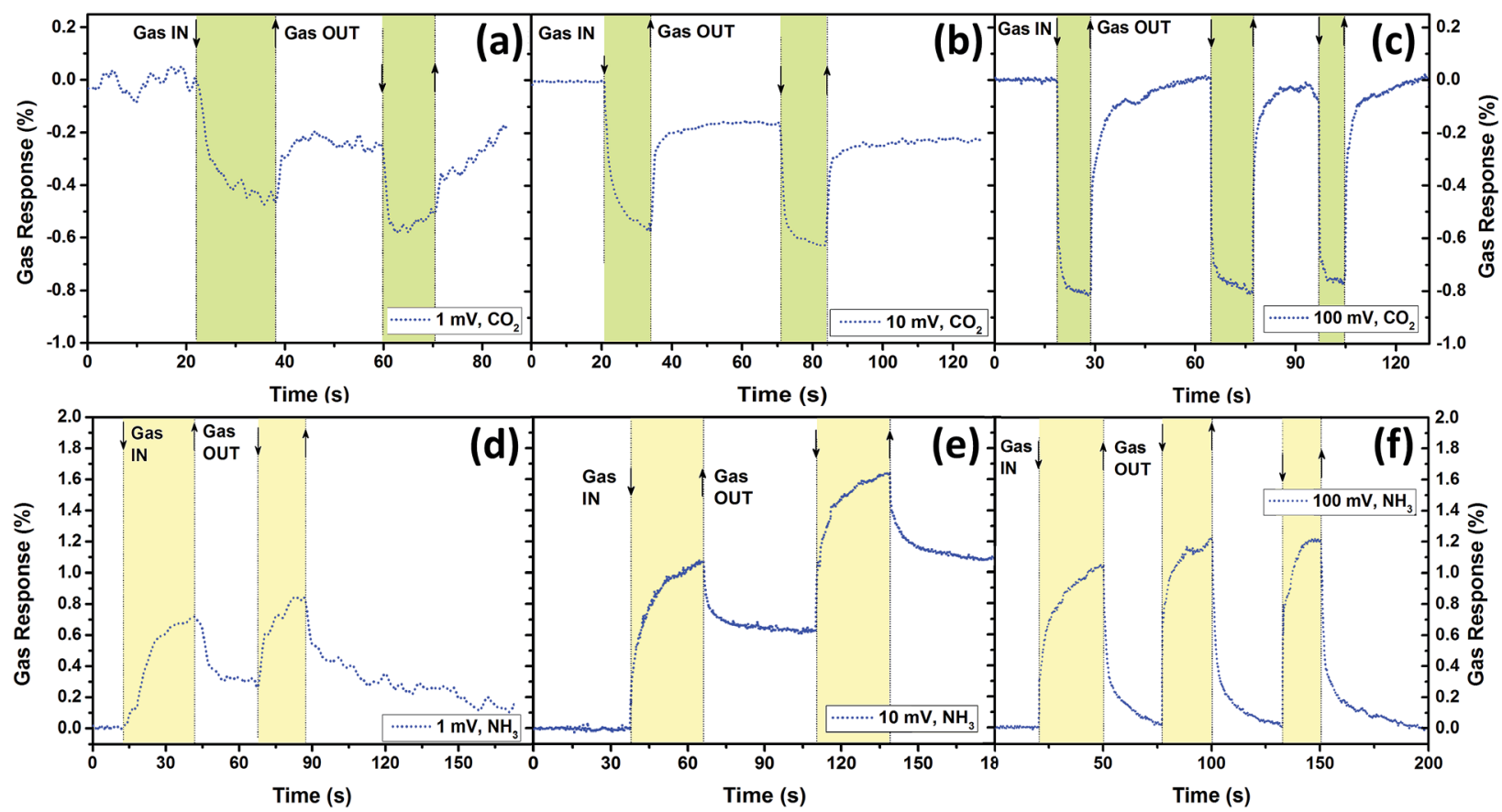

Fig. 3 Dynamic $\mathrm{CO}_{2}$ gas response of the aerographite based sensor at room temperature for: (a) $1 \mathrm{mV}$, (b) $10 \mathrm{mV}$, and (c) $100 \mathrm{mV}$ applied bias. Dynamic $\mathrm{NH}_{3}$ gas response of the aerographite based sensor at room temperature for: (d) $1 \mathrm{mV}$, (e) $10 \mathrm{mV}$, and (f) $100 \mathrm{mV}$ applied bias voltage (concentrations of gases are the following: $\mathrm{CO}_{2}-500$ ppm, $\mathrm{NH}_{3}-100 \mathrm{ppm}$, and $\mathrm{H}_{2}-10000 \mathrm{ppm}$ ). 
and $\mathrm{CH}_{4}$ ), which act as localized temporary dopants to the graphite layers and decrease or increase the concentration of holes, resulting in increased or decreased sample resistance, respectively. ${ }^{37}$ Oxidizing gas molecules such as $\mathrm{CO}_{2}$ are electronwithdrawing and decrease the resistance of aerographite by enhancing doping level, while reducing gas molecules such as $\mathrm{NH}_{3}$ and $\mathrm{H}_{2}$ are electron-donating and act vice versa. ${ }^{38}$ One of the important advantages of the free standing aerographite, compared to graphene based gas sensors, is that the type of substrate does not play any role in tuning of material properties due to charge transfer. ${ }^{37}$

Fig. 4 shows the dynamic response of the sensors at $1 \mathrm{~V}, 3 \mathrm{~V}$, and $5 \mathrm{~V}$ applied bias voltages at room temperature with an indication of the type and concentration of the tested gases. Several consecutive pulses of each type of gas were applied to check the repeatability of the sensor. All calculated parameters (gas response with response and recovery times) are generalized in Table S1 and Fig. S7. $\dagger$ Faster response/recovery times for $3 \mathrm{~V}$
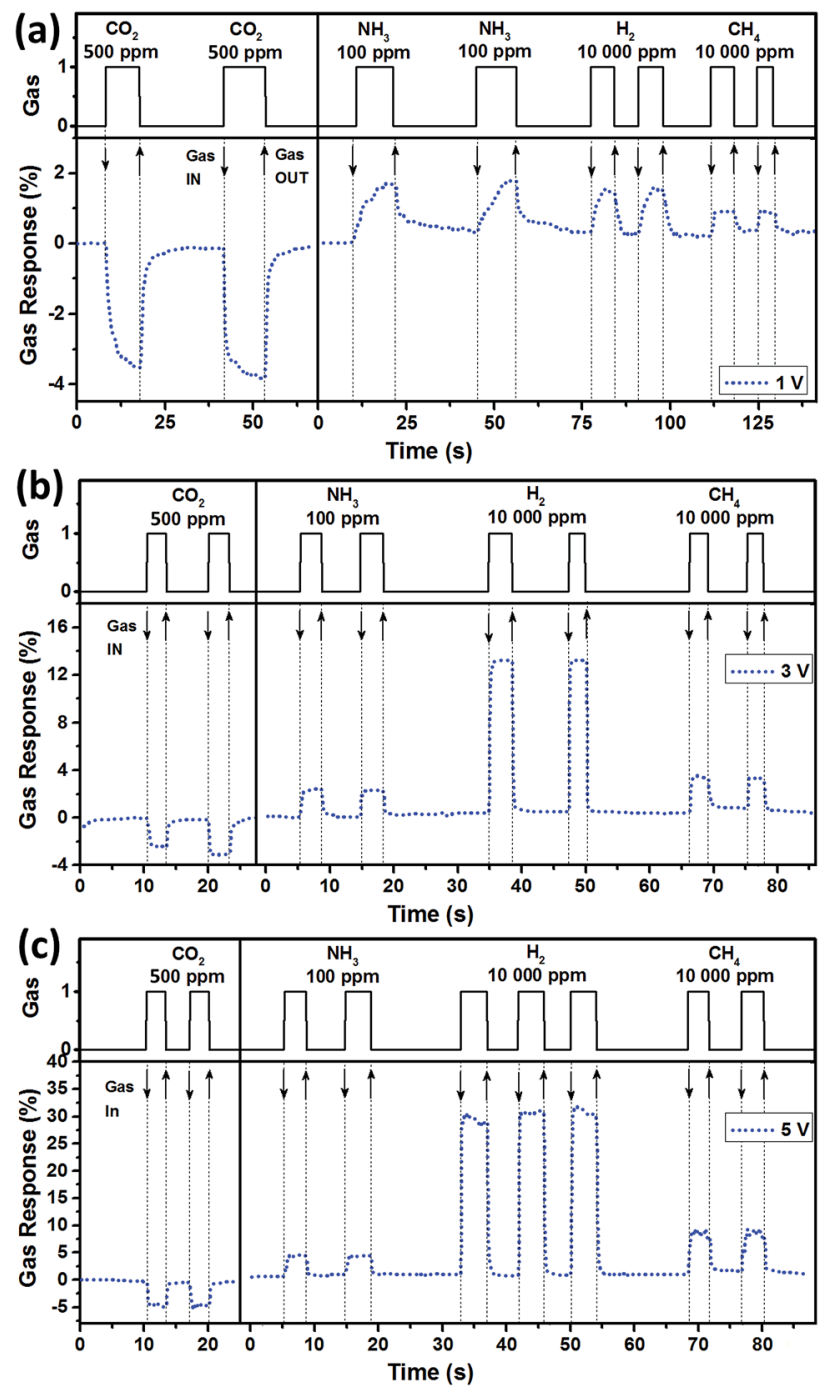

Fig. 4 Dynamic gas response of interconnected graphitic tetrapods an aerographite based sensor at room temperature at the following applied bias voltages: (a) $1 \mathrm{~V}$; (b) $3 \mathrm{~V}$; and (c) $5 \mathrm{~V}$. and $5 \mathrm{~V}$ applied bias voltages can be attributed to a local increase of temperature due to the higher current values through the sample, leading to increased ionization of the tested gases as well as increased adsorption/desorption rates at the surface of the graphite walls. ${ }^{15,16}$ The dynamic response to lower concentrations of $\mathrm{H}_{2}$ and $\mathrm{CH}_{4}$ gases are presented in Fig. S6d, $\uparrow$ showing the same fast response and recovery and capability to detect lower concentrations. On the basis of experimental information (from Fig. S4a and S5a $\dagger$ ), the $3 \mathrm{~V}$ and $5 \mathrm{~V}$ bias voltages applied to the sensor structure based on aerographite from sample set $\mathrm{A}$ are estimated to increase the average sensing material temperature by $\approx 150{ }^{\circ} \mathrm{C}$ and $\approx 275^{\circ} \mathrm{C}$, respectively. In order to confirm this fact, the $\mathrm{H}_{2}$ gas sensing measurements were performed at operating temperatures of $175{ }^{\circ} \mathrm{C}$ and $300{ }^{\circ} \mathrm{C}$ using an external heater and $0.1 \mathrm{~V}$ applied bias voltage (Fig. S8†), showing no significant differences in rapidity and gas response values.

In Table 1, the sensor parameters are compared with other values for carbon based nanomaterials reported in the literature. As can be observed, even at a $1 \mathrm{~V}$ applied bias voltage, the developed sensor structures demonstrated a rapid gas response with good recovery, stability, and repeatability. For $\mathrm{CO}_{2}$ gas sensing, the response and recovery times are $3.98 \mathrm{~s}$ and $6.92 \mathrm{~s}$. Most of the reported results on graphene based sensors demonstrated relatively slow response and recovery times on the order of minutes (see Table 1) and suffered from incomplete recovery. Thus, different methods are applied to reduce the recovery time, such as illumination with infrared (IR) or ultraviolet (UV) light. ${ }^{15,18}$ In our case, we similarly exposed the developed sensor structures to IR and UV illumination but, as expected, no effect was observed in the change of electrical resistivity and recovery time of the investigated devices (not shown here). By increasing the value of applied bias voltage up to $5 \mathrm{~V}$, a considerable increase in the rapidity of the sensors was observed with response and recovery times of about $1 \mathrm{~s}$ (Table $\mathrm{S} 1 \dagger$ ). For example, at $5 \mathrm{~V}$ applied bias voltage, the unprecedentedly ultra-fast response at room temperature of a sensor with a response time and recovery time of $0.25 \mathrm{~s}$ and $0.35 \mathrm{~s}$ was obtained. This is superior to the rapidity values of other sensors based on carbon nanomaterials reported to date (see Table 1) and even other sensors based on oxide semiconductors. ${ }^{39-42}$

Carbon based sensing nanomaterials are known to possess a low gas response to $\mathrm{H}_{2}$ gas at room temperature. ${ }^{\mathbf{1 , 9 , 1 6}}$ Thus, to increase room temperature hydrogen gas sensing performance, surface functionalization with Pd or Pt nanoparticles ${ }^{\mathbf{1}, 9}$ was used previously. As demonstrated, additional steps in sensor fabrication to increase the $\mathrm{H}_{2}$ gas response are not necessary in our case due to the room-temperature (RT) $\mathrm{H}_{2}$ gas sensitivity, which is a very important advantage of the developed multifunctional devices.

In our case, such high hydrogen gas response at $3 \mathrm{~V}$ and $5 \mathrm{~V}$ applied bias voltage can be explained by the excellent hydrogen storage properties of the tubular carbon based nanomaterials, such as SWCNT. ${ }^{\mathbf{4 3 - 4 5}}$ Thus, further investigations are required in this domain for this type of graphene/nanographite material (microscopic tubes with nanoscopic wall thicknesses $\approx 15 \mathrm{~nm}$ ). 
Table 1 Gas sensing properties of carbon based materials

\begin{tabular}{|c|c|c|c|c|c|c|c|}
\hline $\begin{array}{l}\text { Structure, morphology, and properties } \\
\text { of sensing material }\end{array}$ & $\begin{array}{l}\text { Tested gas } \\
\text { (ppm) }\end{array}$ & $\begin{array}{l}\text { Gas } \\
\text { response } \\
\Delta R / \\
R_{\text {gas }} 100 \%\end{array}$ & $\begin{array}{l}\text { Operating temperature/ } \\
{ }^{\circ} \mathrm{C}\end{array}$ & $\begin{array}{l}\text { Response } \\
\text { time } \\
\tau_{\mathrm{r}} / \mathrm{s}\end{array}$ & $\begin{array}{l}\text { Recovery } \\
\text { time } \\
\tau_{\mathrm{d}} / \mathrm{s}\end{array}$ & $\begin{array}{l}\text { Year of } \\
\text { publication }\end{array}$ & Ref. \\
\hline Pd/SW-CNTs & $\mathrm{H}_{2}, 500$ & 23 & $\mathrm{RT}$ & - & - & 2005 & 1 \\
\hline PANI-SWNTs & $\mathrm{NH}_{3}, 100$ & 40 & $\mathrm{RT}$ & $>300^{a}$ & $>300^{a}$ & 2006 & 6 \\
\hline SWNT-PABS & $\mathrm{NH}_{3}, 100$ & $\sim 70^{a}$ & $\mathrm{RT}$ & $\sim 120^{a}$ & $\sim 120^{a}$ & 2007 & 8 \\
\hline Pt/f-MWNT & $\mathrm{H}_{2}, 40000$ & 8 & RT & $\sim 420$ & - & 2009 & 9 \\
\hline Pt/f-graphene & $\mathrm{H}_{2}, 40000$ & 16 & $\mathrm{RT}$ & $\sim 540$ & - & & \\
\hline Graphene sheet & $\mathrm{CO}_{2}, 100$ & 26 & $\mathrm{RT}$ & 8 & - & 2011 & 14 \\
\hline $3 \mathrm{D}$ graphene foam network & $\mathrm{NH}_{3}, 1000$ & 30 & RT & $\sim 500$ & $\sim 800$ & 2011 & 15 \\
\hline \multirow[t]{3}{*}{ Graphene (CVD) } & $\mathrm{NH}_{3}, 75$ & 3 & 150 & 228 & 252 & 2011 & 16 \\
\hline & $\mathrm{CH}_{4}, 37500$ & 3.75 & 200 & $\sim 450$ & $\sim 500$ & & \\
\hline & $\mathrm{H}_{2}, 37500$ & 7.2 & 200 & 264 & 432 & & \\
\hline $\begin{array}{l}\text { Graphene film decorated with Pd } \\
\text { nanoparticles }\end{array}$ & $\mathrm{NH}_{3}, 58$ & 12 & $\mathrm{RT}$ & $\sim 900^{a}$ & $>3000^{a}$ & 2012 & 18 \\
\hline Graphene nanomesh & $\mathrm{NH}_{3}, 100$ & $\sim 13^{a}$ & $\mathrm{RT}$ & $>300^{a}$ & $>300^{a}$ & 2012 & 19 \\
\hline Fluorinated graphene (CVD) & $\mathrm{NH}_{3}, 100$ & 3.8 & $\mathrm{RT}$ & 30 & $<200$ & 2016 & 20 \\
\hline \multicolumn{8}{|l|}{ Aerographite sample A } \\
\hline $0.001 \mathrm{~V}$ & $\mathrm{NH}_{3}, 100$ & 0.71 & $\mathrm{RT}$ & 19.33 & 164 & This work & - \\
\hline $0.01 \mathrm{~V}$ & $\mathrm{NH}_{3}, 100$ & 1.05 & & 12.2 & 132 & & \\
\hline $0.1 \mathrm{~V}$ & $\mathrm{NH}_{3}, 100$ & 1.21 & & 8.7 & 11.58 & & \\
\hline $1 \mathrm{~V}$ & $\mathrm{CO}_{2}, 500$ & -3.83 & & 3.98 & 6.92 & & \\
\hline $3 \mathrm{~V}$ & $\mathrm{H}_{2}, 10000$ & 13.22 & & 0.34 & 0.43 & & \\
\hline $5 \mathrm{~V}$ & $\mathrm{H}_{2}, 10000$ & 31.84 & & 0.25 & 0.35 & & \\
\hline
\end{tabular}

In the case of lower applied bias voltage $(<1 \mathrm{~V})$, an incomplete recovery was observed for $1 \mathrm{mV}$ (Fig. 3a and d) and $10 \mathrm{mV}$ (Fig. 3b and e), which is typical for carbon based nanomaterials. $^{15,18}$ However, at $100 \mathrm{mV}$ applied bias voltage, complete recovery can be observed. Besides incomplete recovery, a decrease in response and recovery time with decrease in applied bias voltage was observed (Fig. S7 and Table $\mathrm{S} 1 \dagger$ ). In conclusion, aerographite from sample set A can be used for extra low power consumption sensing applications at very low applied bias voltages (detection of $\mathrm{NH}_{3}$ and $\mathrm{CO}_{2}$ ), while ultra-rapid $\mathrm{H}_{2}$ gas sensors can be obtained at high applied bias voltages from the same material.

Other studied samples (sets B, C, and D with different morphologies and Zn-residue contents, as shown in Fig. S9-S12†) demonstrated less significant sensing properties with high instability and electrical drift at higher applied bias voltages and under exposure to gases and vapour (Fig. S9e-g, S10c-e, and S11e-g $\dagger$ ). As can be observed from Fig. S1, $\dagger$ the samples from set $B$ were synthesized in the same regime, with the difference that the template material used were multi/tetrapodal $\mathrm{ZnO}$ nano- and microstructures (multipod), described in previous work (Fig. S9a-d†). ${ }^{13}$ Sensing devices based on such structures were characterized by low and unstable electrical characteristics. ${ }^{13}$ In our case the lower sensing properties of aerographite from sample set B can be attributed to the lower porosity of the resulting morphology (ZnO multipod networks also demonstrated lower catalytic properties and $\mathrm{UV} / \mathrm{H}_{2}$ gas sensing properties). ${ }^{13}$ The samples from sets $\mathrm{C}$ and $\mathrm{D}$ were synthesized using the same $\mathrm{ZnO}$ template as for samples from set $\mathrm{B}$ ( $\mathrm{ZnO}$ tetrapods/multipods $)^{17}$ which intentionally contain some $\mathrm{ZnO}$ residues at different levels and affect the electrical gas response (see Fig. S10a, b, and S11a-d $\dagger$ ). Fig. S12 $\uparrow$ shows compositional images taken by EDX elemental mapping at the microstructural level of aerographite sample set B from two different areas of the SEM image of the studied region; (b, f) C; (c, g) Zn, and (d, h) O (the scale bar is $10 \mu \mathrm{m}$ for (a-d) and $5 \mu \mathrm{m}$ for $(\mathrm{e}-\mathrm{h})$ ). For sensor device structures based on sample sets $\mathrm{C}$ and $\mathrm{D}$ the same tendency in increase of $\mathrm{H}_{2}$ gas response and rapidity as for sample set A was observed, however the gas response is much lower or comparable (Fig. S10h and S11h $\dagger$ ). Moreover, at an applied bias voltage of $1 \mathrm{mV}$, no response from these samples was observed. Thus, sensor structures based on sample set A are more suitable for gas-sensing applications.

Based on single micro-structures from sample set A (microscopic tubular graphene with nanoscopic wall thicknesses $\approx 15 \mathrm{~nm}$ ), several devices were made for further characterization. Table $\mathrm{S} 2 \dagger$ generalizes the geometrical and electrical parameters of the devices, which were noted as D1, D2, and D3. Both ends of the microtubular graphene structures were placed on different sides of the chip in different electrical contact combinations. D1 has both ends of the carbon tube structure on the Au/Cr pads (see Fig. S13a and $\mathrm{b} \dagger$ ), D2 has one end on the $\mathrm{Au} / \mathrm{Cr}$ pad and the other on the $\mathrm{SiO}_{2} / \mathrm{Si}$ which is contacted with $\mathrm{Pt}$ to $\mathrm{Au} / \mathrm{Cr}$ (see Fig. S13c and $\mathrm{d} \dagger$ ), and D3 has both ends on $\mathrm{SiO}_{2} / \mathrm{Si}$ which are contacted with $\mathrm{Pt}$ to $\mathrm{Au} / \mathrm{Cr}$ pads (see Fig. S13e and $f \dagger$ ). All devices demonstrated typical linear behavior of the current-voltage characteristics due to carbon/Pt or carbon/Au ohmic contacts (see Fig. S14†), similar to devices based on 
aerographite networks (see Fig. $\mathrm{S} 4 \dagger$ ). ${ }^{\mathbf{4 6 , 4 7}}$ An increase of device resistance by a decrease in diameter of the carbon tubular structures was observed (Table S2 $\dagger$ ), typical for tubular structures taking into account that the thickness of carbon walls is the same for all samples (sample set A). The fabricated devices were tested only against $\mathrm{CO}_{2}$ gas, demonstrating a $-4 \%$ gas response at $100 \mathrm{mV}$ applied bias voltage (see Fig. S15†).

\section{Conclusions}

In summary, efficient, ultra-light and reliable $\mathrm{CO}_{2}$ and $\mathrm{H}_{2}$ gas sensors and nanosensor structures, capable of working at room temperature, were developed in this work using a novel method to change/tune the selectivity of aerographite based sensors by a very simple variation of applied bias voltages $(1 \mathrm{~V}, 3 \mathrm{~V}$, and $5 \mathrm{~V})$. Sensor structures on interconnected aerographite as 3-D graphene/nanographite tetrapods rolled up as a 3-D framework material and on a single tetrapod arm were fabricated. The ultra-fast response of the sensors $(\approx 1 \mathrm{~s})$ was attributed to a local increase of temperature due to higher current values through the sample, leading to an increase in ionization of the tested gases and adsorption/desorption rate at the surface of the nanoscopic graphitic walls. The increase in $\mathrm{H}_{2}$ gas response can be attributed to the excellent storage capacities of the tubular graphitic structures with the microscopic diameter of the aerographite and nanoscopic walls. Another important property of this advanced graphite material is its possibility to detect $\mathrm{NH}_{3}$ and $\mathrm{CO}_{2}$ at very low applied bias voltages (1-100 mV), leading to ultra-low power consumption ( $3.6 \mathrm{nW}$ to $35 \mu \mathrm{W})$. This is very important for long term sensing applications. Such a method can be implemented extremely easily in driving electronic circuits and make the final product (a multifunctional sensor) for consumers; it could even be incorporated or connected externally to a smartphone using the same plug-in connector for headphones. Also, the ultra-low power consumption (at a bias voltage of 1-100 $\mathrm{mV}$ ) allows the use of this type of sensor in long term applications where to change the power supply is difficult or too costly. Single micro-tube structures from sample set A (tubular aerographite microstructures with nanoscopic wall thicknesses about $15 \mathrm{~nm}$ ) were integrated in devices on-chip by using different configurations between $\mathrm{Au} / \mathrm{Cr}$ pads and then characterized. We believe that these results can serve as a new step in nanotechnology with ultra-low power consumption, as well as in hydrogen technologies and continuous environmental monitoring.

\section{Acknowledgements}

This research was sponsored partially by the German Research Foundation (DFG) under the schemes AD 183/17-1 and SFB 986 $\mathbf{M}^{3}$ project B1. This research was partly supported by the STCU within the Grant 5989. O. Lupan acknowledges the Alexander von Humboldt Foundation for the research fellowship for experienced researchers 3-3MOL/1148833 STP at the Institute for Materials Science, Kiel University, Germany.

\section{References}

1 S.-O. Jennifer, W. Hung-Ta, S. K. Byoung, W. Zhuangchun, R. Fan, G. R. Andrew and J. P. Stephen, Nanotechnology, 2005, 16, 2218.

2 U. Riebesell, K. G. Schulz, R. G. J. Bellerby, M. Botros, P. Fritsche, M. Meyerhofer, C. Neill, G. Nondal, A. Oschlies, J. Wohlers and E. Zollner, Nature, 2007, 450, 545-548.

3 T. M. L. Wigley and S. C. B. Raper, Nature, 1990, 344, 324327.

4 H. Rodhe, Science, 1990, 248, 1217.

5 S. C. Doney, V. J. Fabry, R. A. Feely and J. A. Kleypas, Annu. Rev. Mar. Sci., 2009, 1, 169-192.

6 T. Zhang, M. B. Nix, B. Y. Yoo, M. A. Deshusses and N. V. Myung, Electroanalysis, 2006, 18, 1153-1158.

7 S. Shafiee and E. Topal, Energy Policy, 2009, 37, 181-189.

8 Z. Ting, M. Syed, B. Elena, Y. B. Young, C. H. Robert, V. M. Nosang and A. D. Marc, Nanotechnology, 2007, 18, 165504.

9 A. Kaniyoor, R. I. Jafri, T. Arockiadoss and S. Ramaprabhu, Nanoscale, 2009, 1, 382-386.

10 S. Dunn, Int. J. Hydrogen Energy, 2002, 27, 235-264.

11 M. Momirlan and T. N. Veziroglu, Int. J. Hydrogen Energy, 2005, 30, 795-802.

12 D. Gedamu, I. Paulowicz, S. Kaps, O. Lupan, S. Wille, G. Haidarschin, Y. K. Mishra and R. Adelung, Adv. Mater., 2014, 26, 1541-1550.

13 Y. K. Mishra, G. Modi, V. Cretu, V. Postica, O. Lupan, T. Reimer, I. Paulowicz, V. Hrkac, W. Benecke and L. Kienle, ACS Appl. Mater. Interfaces, 2015, 7, 14303-14316. 14 H. J. Yoon, D. H. Jun, J. H. Yang, Z. Zhou, S. S. Yang and M. M.-C. Cheng, Sens. Actuators, B, 2011, 157, 310-313.

15 F. Yavari, Z. Chen, A. V. Thomas, W. Ren, H.-M. Cheng and N. Koratkar, Sci. Rep., 2011, 1, 166.

16 M. Gautam and A. H. Jayatissa, Mater. Sci. Eng., C, 2011, 31, 1405-1411.

17 M. Mecklenburg, A. Schuchardt, Y. K. Mishra, S. Kaps, R. Adelung, A. Lotnyk, L. Kienle and K. Schulte, Adv. Mater., 2012, 24, 3486-3490.

18 M. Gautam and A. H. Jayatissa, J. Appl. Phys., 2012, 111, 094317.

19 R. K. Paul, S. Badhulika, N. M. Saucedo and A. Mulchandani, Anal. Chem., 2012, 84, 8171-8178.

20 H. Zhang, L. Fan, H. Dong, P. Zhang, K. Nie, J. Zhong, Y. Li, J. Guo and X. Sun, ACS Appl. Mater. Interfaces, 2016, 8, 86528661.

21 J.-H. Lee, Sens. Actuators, B, 2009, 140, 319-336.

22 I. Hölken, G. Neubüser, V. Postica, L. Bumke, O. Lupan, M. Baum, Y. K. Mishra, L. Kienle and R. Adelung, ACS Appl. Mater. Interfaces, 2016, 8, 20491-20498.

23 A. Schuchardt, T. Braniste, Y. K. Mishra, M. Deng, M. Mecklenburg, M. A. Stevens-Kalceff, S. Raevschi, K. Schulte, L. Kienle and R. Adelung, Sci. Rep., 2015, 5, 8839.

24 C. Lamprecht, M. Taale, I. Paulowicz, H. Westerhaus, C. Grabosch, A. Schuchardt, M. Mecklenburg, M. Böttner, R. Lucius, K. Schulte, R. Adelung and C. Selhuber-Unkel, ACS Appl. Mater. Interfaces, 2016, 8, 14980-14985. 
25 I. Tiginyanu, L. Ghimpu, J. Gröttrup, V. Postolache, M. Mecklenburg, M. A. Stevens-Kalceff, V. Ursaki, N. Payami, R. Feidenhansl, K. Schulte, R. Adelung and Y. K. Mishra, Sci. Rep., 2016, 6, 32913.

26 O. Lupan, G. Chai and L. Chow, Microelectron. Eng., 2008, 85, 2220-2225.

27 H.-M. Cheng, Q.-H. Yang and C. Liu, Carbon, 2001, 39, 14471454.

28 S. Chandrasekaran, W. V. Liebig, M. Mecklenburg, B. Fiedler, D. Smazna, R. Adelung and K. Schulte, Compos. Sci. Technol., 2016, 122, 50-58.

29 T. Kawano, H. C. Chiamori, M. Suter, Q. Zhou, B. D. Sosnowchik and L. Lin, Nano Lett., 2007, 7, 3686-3690.

30 T. J. Kang, T. Kim, S. M. Seo, Y. J. Park and Y. H. Kim, Carbon, 2011, 49, 1087-1093.

31 D. Sui, Y. Huang, L. Huang, J. Liang, Y. Ma and Y. Chen, Small, 2011, 7, 3186-3192.

32 T. Dinh, H.-P. Phan, D. V. Dao, P. Woodfield, A. Qamar and N.-T. Nguyen, J. Mater. Chem. C, 2015, 3, 8776-8779.

33 W. W. Tyler and A. C. Wilson jr, Phys. Rev., 1953, 89, 870.

34 O. Lupan, L. Chow and G. Chai, Sens. Actuators, B, 2009, 141, 511-517.

35 J. Kong, N. R. Franklin, C. Zhou, M. G. Chapline, S. Peng, K. Cho and H. Dai, Science, 2000, 287, 622-625.
36 O. Lupan, V. V. Ursaki, G. Chai, L. Chow, G. A. Emelchenko, I. M. Tiginyanu, A. N. Gruzintsev and A. N. Redkin, Sens. Actuators, B, 2010, 144, 56-66.

37 S. Basu and P. Bhattacharyya, Sens. Actuators, B, 2012, 173, 121.

38 W. Yuan and G. Shi, J. Mater. Chem. A, 2013, 1, 10078-10091.

39 G. K. Mor, M. A. Carvalho, O. K. Varghese, M. V. Pishko and C. A. Grimes, J. Mater. Res., 2004, 19, 628-634.

40 P. A. Russo, N. Donato, S. G. Leonardi, S. Baek, D. E. Conte, G. Neri and N. Pinna, Angew. Chem., Int. Ed., 2012, 51, 1105311057.

41 O. K. Varghese, G. K. Mor, C. A. Grimes, M. Paulose and N. Mukherjeeb, J. Nanosci. Nanotechnol., 2004, 4, 733-737.

42 H. T. Wang, B. S. Kang, F. Ren, L. C. Tien, P. W. Sadik, D. P. Norton, S. J. Pearton and J. Lin, Appl. Phys. Lett., 2005, 86, 243503.

43 A. C. Dillon, K. M. Jones, T. A. Bekkedahl, C. H. Kiang, D. S. Bethune and M. J. Heben, Nature, 1997, 386, 377-379. 44 L. Schlapbach and A. Züttel, Nature, 2001, 414, 353-358.

45 C. Liu, Y. Y. Fan, M. Liu, H. T. Cong, H. M. Cheng and M. S. Dresselhaus, Science, 1999, 286, 1127-1129.

46 S. J. Tans, A. R. M. Verschueren and C. Dekker, Nature, 1998, 393, 49-52.

47 X. Cui, M. Freitag, R. Martel, L. Brus and P. Avouris, Nano Lett., 2003, 3, 783-787. 